\title{
In Situ Study of the Stress Relaxation During Aging of Nickel-Base Superalloy Forgings
}

\author{
P.E. ABA-PEREA, P.J. WITHERS, T. PIRLING, A. PARADOWSKA, D. MA, \\ and M. PREUSS
}

\begin{abstract}
Nickel-base superalloys are conventionally aged in order to develop a favorable microstructure as well as to relieve residual stresses. Here neutron diffraction was used to follow the evolution of residual stress during aging in Inconel 718 and Udimet 720LI for the first time by a combination of in situ and ex situ measurements. First, the quench-induced stress profiles were determined for different geometries of Inconel 718 forgings confirming that the amplitude of stress is not significantly affected by the thickness of the component. It was followed by in situ residual stress analysis using neutron diffraction during aging/annealing treatments at $650{ }^{\circ} \mathrm{C}$, $720^{\circ} \mathrm{C}$, and $750^{\circ} \mathrm{C}$. Almost 90 pct of stress relaxation was found to occur primarily during heating to the aging temperature as a result of a combination of plasticity and early-stage creep relaxation. Creep-like stress relaxation was observed to evolve at a diminishing rate during the isothermal treatment of Inconel 718 at $720{ }^{\circ} \mathrm{C}$ and $750{ }^{\circ} \mathrm{C}$, while no further stress relaxation occurred at $650^{\circ} \mathrm{C}$. This means that a change in hold temperature might have a more immediate impact on stress relaxation than a change in duration of heat treatment. The post-aging ex situ measurements showed that a heat treatment at $750{ }^{\circ} \mathrm{C}$ for 8 hours reduced the stresses by approximately 70 pct in Inconel 718. By comparison, when heat treating Udimet 720LI in the same way only a 20 pct stress reduction was observed, which is explained by the higher creep resistance of this alloy.
\end{abstract}

https://doi.org/10.1007/s11661-019-05302-0

(C) The Minerals, Metals \& Materials Society and ASM International 2019

P.E. ABA-PEREA is with the Institut Max Von Laue - Paul Langevin, 71 Avenue des Martyrs 38000 Grenoble, France and also with the School of Materials, University of Manchester, Manchester, M13 9PL, UK. Contact e-mail: pierre.abaperea@gmail.com P.J. WITHERS and M. PREUSS are with the School of Materials, University of Manchester. T. PIRLING is with the Institut Max Von Laue - Paul Langevin. A. PARADOWSKA is with the OPAL, Ansto, Kirrawee DC, NSW 2232, Australia. D. MA is with the Neutron Scattering Division, Spallation Neutron Source, Oak Ridge National Laboratory, TN 37831-6139.

Manuscript submitted November 28, 2018.

This manuscript has been authored by UT-Battelle, LLC under Contract No. DE-AC05-00OR22725 with the U.S. Department of Energy. The United States Government retains and the publisher, by accepting the article for publication, acknowledges that the United States Government retains a non-exclusive, paid-up, irrevocable, world-wide license to publish or reproduce the published form of this manuscript, or allow others to do so, for United States Government purposes. The Department of Energy will provide public access to these results of federally sponsored research in accordance with the DOE Public Access Plan (http://energy.gov/dow nloads/doe-public-access-plan).

Article published online June 3, 2019

\section{INTRODUCTION}

NI-BASE superalloys are widely used for aeroengine applications and in the energy sector due to their exceptional mechanical strength and creep resistance at high temperature. ${ }^{[1]}$ Depending on the microstructure, temperature capability, and mechanical property requirements, different superalloys are used for the manufacturing of disks and blades for the hot section of aeroengines. Inconel 718 and Udimet 720LI are among the most widely used Ni-base superalloys. Inconel 718 is strengthened by having a combination of $\gamma^{\prime \prime}$ and $\gamma^{\prime}$ precipitates amounting to about $25 \mathrm{vol} \mathrm{pct,}{ }^{[2]}$ while Udimet $720 \mathrm{LI}$ is strengthened by approximately 45 vol pct of $\gamma^{\prime} .{ }^{3]}$ The high-volume fractions of these precipitates allows these alloys to operate under extreme mechanical conditions at temperatures exceeding $600{ }^{\circ} \mathrm{C}$ in the case of Udimet $720 \mathrm{LI} .^{[1]}$ The manufacturing process of polycrystalline Ni-base superalloy components typically involves several thermomechanical steps, many of which result in the generation of significant residual stresses. In particular, processes such as forging followed by quenching/fast cooling generate very high level of residual stress in Ni-base superalloys. ${ }^{[47]}$ Consequently, there is a requirement to precisely control and minimize the residual stress distribution because they can lead to distortion during machining and they 
superimpose on the operating stresses which can significantly reduce component life in-service. ${ }^{[8]}$

Residual stresses are mitigated by means of thermal stress relaxation through the application of an annealing treatment, which also serves the purpose of an aging treatment precipitating or optimizing the distribution of the before mentioned strengthening phases, ${ }^{[9,10]}$ A comparative study of residual stresses induced by inertia friction welding and subsequent thermal relaxation of these stresses by post-welding heat treatment (PWHT) was carried out by Preuss et al. ${ }^{[11]}$ The applied PWHTs were performed at temperatures close to the usual aging temperature. That work demonstrated the effect of alloy chemistry, and therefore temperature capability of the alloy, on the generation of residual stress during inertia friction welding and the relaxation of stress during the post-welding heat treatment. The maximum tensile hoop stress was measured to be 700, 1000, and $1500 \mathrm{MPa}$ for the as-welded Inconel 718, Udimet 720LI, and RR1000, respectively. In order to sufficiently reduce these stresses, i.e., to below $400 \mathrm{MPa}$ in this particular case, the PWHT temperature had to be adjusted according to the alloy. In the case of Udimet 720LI and RR1000, this meant aging temperatures of about $30{ }^{\circ} \mathrm{C}$ and $80{ }^{\circ} \mathrm{C}$ higher than that for Inconel 718, respectively. Other ex situ studies have focused on the evolution of residual stresses during aging heat treatments: in Reference 12 the thermal residual stress relaxation in inertia friction-welded Udimet 720LI was investigated by measuring the stresses in several samples treated at the same temperature, but for different durations. While overall the expected trends of stress relaxation with time were observed, the work also highlighted significant issues with sample-to-sample variations. Thermal stress relaxation was also probed in a René 95 superalloy disk by X-ray diffraction for a single component and an interrupted heat treatment procedure. ${ }^{[3]}$ These surface residual stress measurements suggested that the stresses can be reduced by 70 pct when the component is annealed at $704{ }^{\circ} \mathrm{C}$ for 500 hours. However, it is unclear from that work if similar levels of stress relaxation can also be achieved in the bore of the disk where there might be hydrostatic stress conditions.

Neutron diffraction is a powerful non-destructive method that enables the characterization of residual stresses in multiple directions in large engineering components. ${ }^{[14]}$ Rolph et al. were probably the first to carry out in situ measurements of stress relaxation looking at water-quenched hockey puck RR1000 samples. ${ }^{[15]}$ Stress relaxation was recorded in the center of the hockey puck sample during a heat treatment at $750{ }^{\circ} \mathrm{C} / 8$ hours. Despite a significant scatter of the data arising from a strong attenuation of the beam during the in situ measurements, a clear trend of the stress relaxation evolution was observed.

A detailed picture of the relaxation of stress during heating to, and holding at, the annealing temperature can provide key information about how best to tailor aging treatments that simple post-anneal stress measurements cannot do. Further, such in situ data are ideal to validate process models designed to predict residual stresses on full-scale components.
In the present study, the development of quench-induced residual stresses and the subsequent thermal stress relaxation during aging of Inconel 718 and Udimet 720LI hockey puck samples was investigated by a combination of ex situ and in situ measurements. The aim of the present work is to understand the influence of sample geometry on the development of residual stresses in superalloys during quenching and aging as well as the influence of aging temperature on stress relaxation rate. The stress measurements were carried out by means of neutron diffraction. In the case of ex situ analysis, hockey puck samples were scanned along the center line in the axial and radial direction. For the in situ aging analysis, a new heat treatment setup was applied designed to be accommodated on neutron strain scanning beam lines. Due to the large number of measurements involved in this study, the measurements were carried out on three different strain scanning instruments. The time-of-flight (TOF) instrument VULCAN at SNS, Oak Ridge, US ${ }^{[16]}$ was used to study the temperature dependence of the stress relaxation rate in Inconel 718. The monochromatic instrument KOWARI at ANSTO, Kirrawee DC, Australia, ${ }^{[17]}$ was used to investigate the influence of sample geometry on the development and relaxation of stresses. Finally, the monochromatic instrument SALSA at the ILL, Grenoble, France, ${ }^{[18]}$ was used to study Udimet 720LI to compare stress relaxation between Inconel 718 and Udimet 720LI.

\section{EXPERIMENTAL PROCEDURE}

\section{A. Materials, Specimen, and Treatments}

Inconel 718 and Udimet 720LI were provided by Aubert\&Duval having the nominal chemical compositions summarized in Table I. ${ }^{[1]}$ The pucks (disks) were extracted from large Inconel 718 and Udimet 720LI pancake forgings having an approximately random crystallographic texture. The geometry of the pucks is presented in Figure 1 with all samples having a diameter of $126 \mathrm{~mm}$, but their thickness varying from 15 to $25 \mathrm{~mm}$. The solution treatments and quenching were applied to each sample separately using exactly the same procedure. In the case of Inconel 718, the solution treatment consisted of a sub- $\delta$-solvus treatment at $980{ }^{\circ} \mathrm{C}$ for 1 hour followed by water quenching. Due to improved temperature capability, Udimet 720LI has the ability to develop higher residual stress levels than Inconel 718 and drastic cooling such as water cooling may result in crack initiation. Therefore, the Udimet 720LI samples were oil quenched after the usual sub- $\gamma^{\prime}$-solvus treatment at $1100{ }^{\circ} \mathrm{C} / 4$ hours.

The standard industrial aging treatments applied to these two alloys is often a two-step heat treatment in a temperature range between $620^{\circ} \mathrm{C}$ and $760{ }^{\circ} \mathrm{C}$ and between 8 to 24 hours depending on the required properties. Previous studies have shown that most of the stress relaxation occurs during the first hours of the treatment. ${ }^{[15,20,21]}$ Table II summarizes the dimensions and starting condition of all samples (S1-S10), the 
Table I. Nominal Chemical Compositions of Inconel 718 and Udimet 720LI Superalloys in Weight Percent ${ }^{[1]}$

\begin{tabular}{lcccccccccccc}
\hline Alloys & $\mathrm{Ni}$ & $\mathrm{Cr}$ & $\mathrm{Fe}$ & $\mathrm{Mo}$ & $\mathrm{Co}$ & $\mathrm{Nb}$ & $\mathrm{Al}$ & $\mathrm{Ti}$ & $\mathrm{W}$ & $\mathrm{C}$ & $\mathrm{Other}$ \\
\hline Udimet 720 LI & 57.0 & 16.0 & & 3.0 & 15.0 & - & 2.5 & 5.0 & 1.25 & 0.025 & $0.03 \mathrm{Zr}$ \\
Inconel 718 & 52.5 & 19.0 & 18.5 & 3.0 & - & 5.1 & 0.5 & 0.9 & - & 0.08 & $0.15 \mathrm{Max} \mathrm{Cu}$ \\
\hline
\end{tabular}

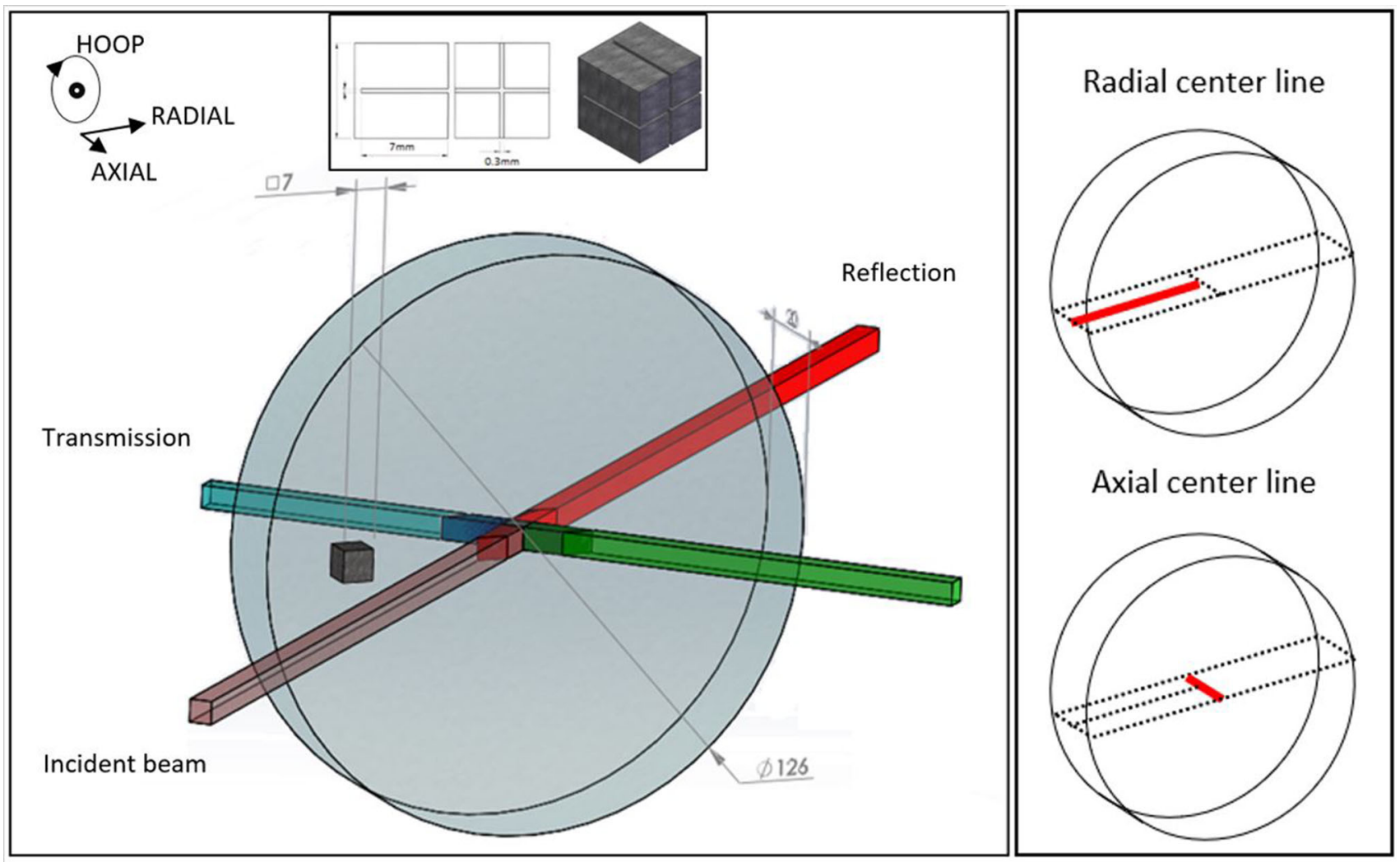

Fig. 1 -Design of the hockey puck sample, the $d_{0}$ reference sample and position of the beam during measurements, ${ }^{[19]}$ and scan lines for $e x$ situ measurements (all dimensions in $\mathrm{mm}$ ).

instruments used for the stress analysis of each sample, as well as the in situ measurements' conditions.

\section{B. Strain Measurements by Neutron Diffraction}

All strain measurements were carried out using the $\mathrm{Ni}(311)$ reflection, which is known to be least sensitive to intergranular strain accumulation and hence representative of the bulk behavior for Nickel-base superalloys. $^{[22]}$ In the case of ex situ measurements, the stress-free d-spacing was generally measured in two directions in five different reference samples which were extracted from different locations of the hockey puck samples to obtain good statistics. In the present work, the ex situ $d_{0}$ measurements were used to calibrate the strain measurements from the three instruments and ensure the metrological comparison of the different data sets. In situ measurements required monitoring of $d_{0}$ evolution as a function of temperature, which is described in more detail below.
VULCAN, based at the Spallation Neutron Source (SNS), Oak Ridge National Laboratory, $\mathrm{US}^{[16]}$ is a Time-of-flight (TOF) engineering diffractometer with two detector banks fixed at a $-/+90$ deg angle to the incident beam, simultaneously giving two scattering vectors (strain measurement direction) - one parallel and the other perpendicular to the surface of the sample when aligned at $45 \mathrm{deg}$ to the incident beam). In the present study, the chopper of the VULCAN instrument was set to $60 \mathrm{~Hz}$ corresponding to a center wavelength of $1.5 \AA$ and a bandwidth of $1.44 \AA$ in order to access the $\mathrm{Ni}(311)$ reflection with maximized incident fluxes. Due to the homogeneous stress field expected in the center of the samples, it was possible to choose a large gauge volume defined by $5 \times 5 \mathrm{~mm}^{2}$ slits on the primary beam size and 5-mm-wide radial collimators on the detectors sides. This maximized the neutron flux and hence minimized counting times. Initially, a series of measurements were carried out to determine the stress profile introduced by water quenching in S1, S2, and S3 


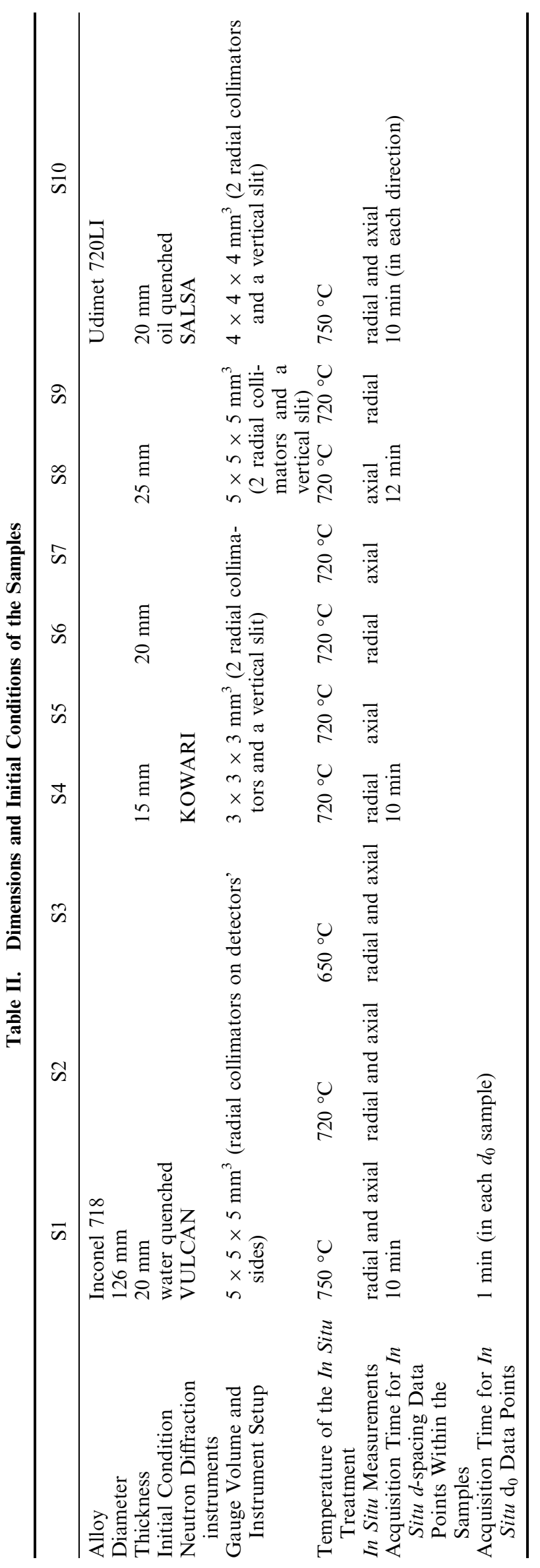

(Inconel 718, 20-mm-thick samples). For this purpose, the center line was scanned in the axial direction of the hockey puck samples. Subsequently, the three samples were used for in situ annealing experiments at $650{ }^{\circ} \mathrm{C} /$ 8 hours, $720^{\circ} \mathrm{C} / 8$ hours, and $750{ }^{\circ} \mathrm{C} / 8$ hours.

KOWARI, based at the neutron reactor source OPAL, ANSTO, Australia, is a monochromatic instrument. ${ }^{[17]}$ The wavelength was set at $1.54 \AA$ to access the $\mathrm{Ni}(311)$ diffraction peak at a $2 \theta$ angle of approximately $90 \mathrm{deg}$. A $3 \times 3 \times 3 \mathrm{~mm}^{3}$ diffracting gauge volume was defined for the 15-mm-thick samples, S4 and S5, and the 20-mm-thick samples, $\mathbf{S} 6$ and $\mathbf{S 7}$, by slits and a radial collimator on the detector side. For the 25-mm-thick samples, S8 and S9, a $5 \times 5 \times 5 \mathrm{~mm}^{3}$ gauge was used. The radial, hoop, and axial stress profiles were determined for the waterquenched condition along the radial center line of the samples. Subsequently, in situ heat treatments at $720^{\circ} \mathrm{C} /$ 8 hours were applied to each sample and measurements were carried out at the center of the hockey puck. The location was chosen because the stress field can be expected to be most homogeneous in this region and an equi-biaxial in-plane strain field means that only two strain directions had to be measured (radial and axial) to calculate stress. As it is not possible to measure two strain directions simultaneously using a monochromatic source, two samples were required in order to separately carry out in situ measurements in the in-plane (radial) and axial directions. Consequently, the stress evolution was calculated on the basis of strains measured in two samples. After cooling, one sample of each thickness was mounted on the sample stage to determine the stress profile post heat treatment.

The third instrument utilized in this study was SALSA ${ }^{[18]}$ which is also a monochromatic instrument based at the ILL neutron reactor source, Grenoble, France. Here a wavelength of $1.55 \AA$ was chosen, similar to that used on KOWARI. For both the ex situ and in situ measurements on Udimet 720LI (S10), a $4 \times 4 \times 4 \mathrm{~mm}^{3}$ gauge was selected by vertical slits and radial collimators. First, the stress profile in the oil-quenched Udimet 720LI sample was determined along the radial center line and the axial center line. The fast rotation of the sample stage on SALSA meant that the radial/hoop and axial strain directions could be measured alternatively on one sample (S10) during the in situ experiment. As described for the in situ measurements carried out on KOWARI, measurements were carried out in the center of the hockey puck.

\section{In Situ Experimental Setup and Procedure}

The in situ experiment setup is described in detail in Reference 19. In brief, it comprises an induction heating system, which consists of a double spire coil linked to an impedance adaptor, a RF amplifier, and an external control panel. The samples are mounted on a sample holder specifically designed for this experiment. Porous alumina and silica plates with low neutron beam attenuation properties are used for the thermal insulation in order to ensure thermal homogeneity over the sample. Temperature control is achieved using two K-type thermocouples which are inserted $5 \mathrm{~mm}$ under 


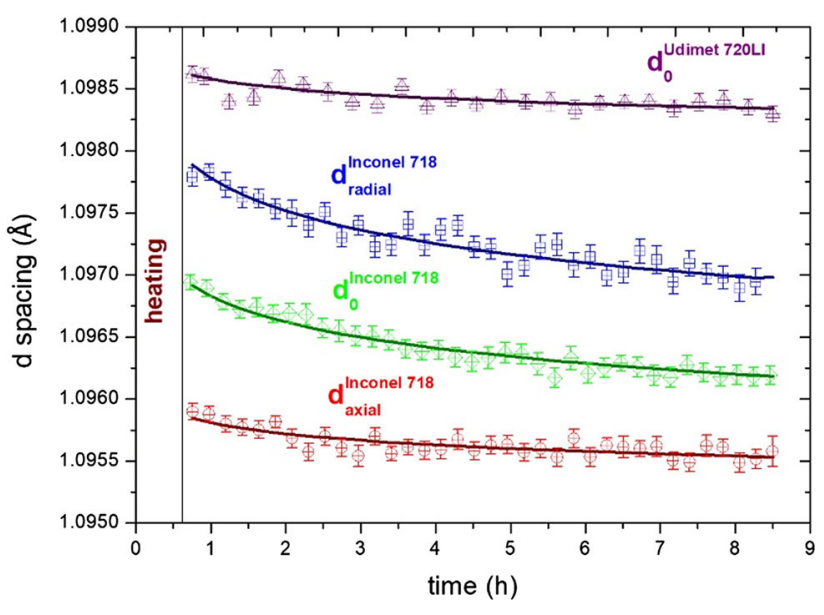

Fig. 2-Evolution of $d$-spacing and $d_{0}$ with time during annealing S1 (Inconel 718) at $750{ }^{\circ} \mathrm{C}$ for $8 \mathrm{~h},{ }^{[19]}$ and evolution of the $d_{0}$ with time during annealing of Udimet $720 \mathrm{LI}$ at $750{ }^{\circ} \mathrm{C}$ for $8 \mathrm{~h}$.

the surface of the samples. The holes for the thermocouples were drilled by spark erosion far from the center of the sample in order to minimize the impact on the stress distribution. Radial induction heating means that the rim of the sample will heat faster than its core. The thermal gradient in the sample during heating reached a maximum of $200{ }^{\circ} \mathrm{C}$ with such setup and sample geometry. ${ }^{[19]}$ Therefore, the first in situ data were collected after 40 minutes which is the required time to reach isothermal condition in the sample.

Since the aging treatments promote the precipitation of strengthening phases, an evolution of the stress-free $d$-spacing $\left(d_{0}\right)$ is expected to occur during the in situ measurements. ${ }^{[23]}$ This was monitored in two $d_{0}$ samples (as shown in Figure 1) glued on the surface of each of the stressed samples. An additional thermocoupled reference sample with the same geometry was glued next to the $\mathrm{d}_{0}$ samples in order to monitor the temperature of the reference samples. The $d_{0}$ samples and the disk sample were carefully aligned in the radial and hoop directions before placing the insulation. After clamping the two alumina-silica plates to the sample holder, the axial direction was aligned by carrying out entry scans. Heating to the dwell temperature generally took around $40 \mathrm{~min}$ utes. Once the target temperature was reached, measurements at the center of the disk and in the reference samples were alternated. All heat treatments were applied for 8 hours after reaching the target temperature, after which the furnace was turned off and the insulation material removed when the temperature was around $500{ }^{\circ} \mathrm{C}$. Once the samples were at room temperature, they were scanned again in order to obtain a post-aging stress profiles for comparison to the as-quenched ones.

\section{Diffraction data analysis}

Data analysis was carried out using the in-house softwares of each instrument, VDRIVE, QKowari, and LAMP for VULCAN, KOWARI, and SALSA instruments, respectively. For consistency, a single peak fit of the (311) diffraction peak was used for both monochromatic and TOF data.
Figure 2 shows the variation in d-spacing during annealing at $750{ }^{\circ} \mathrm{C}$ at the center of the Inconel 718 puck (S1) and for the strain-free reference sample in Inconel 718 and Udimet 720LI. It is noteworthy that $\mathrm{d}_{0}$ of Inconel 718 decreases by more than $7 \times 10^{-4} \AA$ during the treatment (equating to $\sim 650 \times 10^{-6}$ strain) compared to changes in lattice spacing of $3.5 \times 10^{-4} \AA$ and $9 \times 10^{-4} \AA$ in the axial and radial directions, respectively, for the Inconel 718 puck. Hence, a significant proportion of $d$-spacing variation measured in the stressed sample of Inconel 718 is due to the microstructure evolution and not related to the relaxation of residual stress. On the other hand, $d_{0}$ of Udimet 720LI decreases by only $2.5 \times 10^{-4} \AA$ during 8-hour annealing at $750{ }^{\circ} \mathrm{C}$. Therefore, the treatment only induces minor microstructure evolution in Udimet 720LI compared to Inconel 718. The assumption is made that the stress field in the puck samples has a negligible influence on the precipitation of the strengthening phases throughout the heat treatment, i.e., it is assumed that the microstructure evolves at the same rate at the center of the puck and in the stress-free samples. The average uncertainty in $\mathrm{d}$-spacing in the radial and axial directions for Inconel 718 corresponds to approximately $75 \times 10^{-6}$ strain and it is almost the double for Udimet 720LI which promotes more neutron absorption. ${ }^{[19]}$ This uncertainty is related to the goodness of peak fit and was calculated with the following equation ${ }^{[24]}$ :

$$
U_{\varepsilon}=\frac{1}{d_{0}}\left[(\delta d)^{2}+\left(\delta d_{0}\right)^{2}\right]^{1 / 2},
$$

where $\delta d$ is the fitting uncertainty in the lattice parameter and $\delta d_{0}$ is the fitting uncertainty in the stress-free lattice parameter. This does not include other systematic sources of error such as positioning errors or the errors in temperature measurements. The scatter remained relatively low throughout the heat treatment; however, it is significant when compared to the variation of $d$-spacing due to the stress relaxation. Therefore, the $d$-spacing evolutions were fitted with logarithmic curves as shown in Figure 2, which were then used to calculate the evolution of elastic strain. The elastic strain $\varepsilon$ was calculated using

$$
\varepsilon(t)=\frac{d^{h k l}(t)-d_{0}^{h k l}(t)}{d_{0}^{h k l}(t)},
$$

from which the stress $\sigma$ in each direction was calculated using the following relation ${ }^{[8]}$ :

$$
\begin{aligned}
\sigma_{\text {radial }}= & \frac{E_{h k l}}{\left(1-v_{h k l}\right)\left(1-2 v_{h k l}\right)} \\
& {\left[\left(1-v_{h k l}\right) \varepsilon_{\text {radial }}+v_{h k l}\left(\varepsilon_{\text {axial }}+\varepsilon_{\text {hoop }}\right)\right] } \\
& \text { and } \sigma_{\text {axial }}=\ldots \text { etc }
\end{aligned}
$$

where $E_{h k l}$ is the diffraction elastic constant and $v_{h k l}$ is the plane-specific Poisson's ratio. The stress calculations require the use of suitable Diffraction Elastic Constants (DECs), which are presented in Table III. ${ }^{[25]}$ Since the in situ measurements were carried out in the center of 
Table III. Diffraction Elastic Constants and Plane-Specific Poisson's Ratio of Inconel 718 and Udimet 720 LI at the Studied Temperatures $^{[25]}$

\begin{tabular}{|c|c|c|c|c|c|c|}
\hline \multirow[b]{2}{*}{ Temperature } & \multicolumn{4}{|c|}{ Inconel 718} & \multicolumn{2}{|c|}{ Udimet 720LI } \\
\hline & $20^{\circ} \mathrm{C}$ & $650^{\circ} \mathrm{C}$ & $720^{\circ} \mathrm{C}$ & $750{ }^{\circ} \mathrm{C}$ & $20{ }^{\circ} \mathrm{C}$ & $750{ }^{\circ} \mathrm{C}$ \\
\hline$\overline{E_{311}}$ & $202 \mathrm{GPa}$ & $150 \mathrm{GPa}$ & $130 \mathrm{GPa}$ & $125 \mathrm{GPa}$ & $220 \mathrm{GPa}$ & $155 \mathrm{GPa}$ \\
\hline$v_{311}$ & 0.32 & 0.32 & 0.34 & 0.35 & 0.29 & 0.36 \\
\hline
\end{tabular}

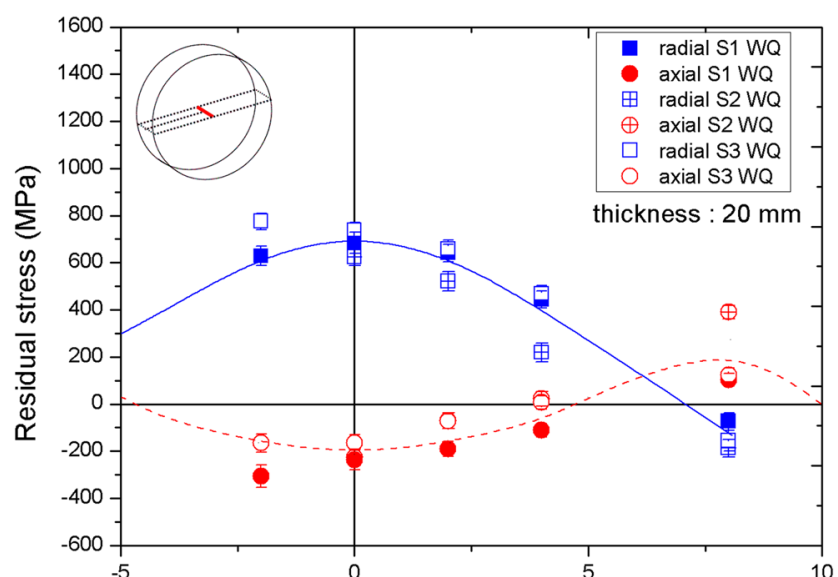

Distance from the geometric center in axial direction $(\mathrm{mm})$

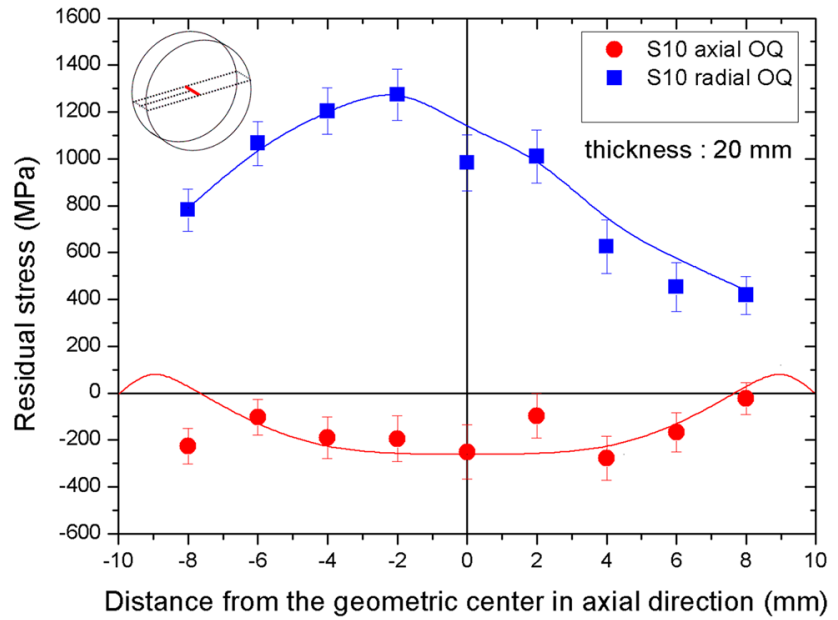

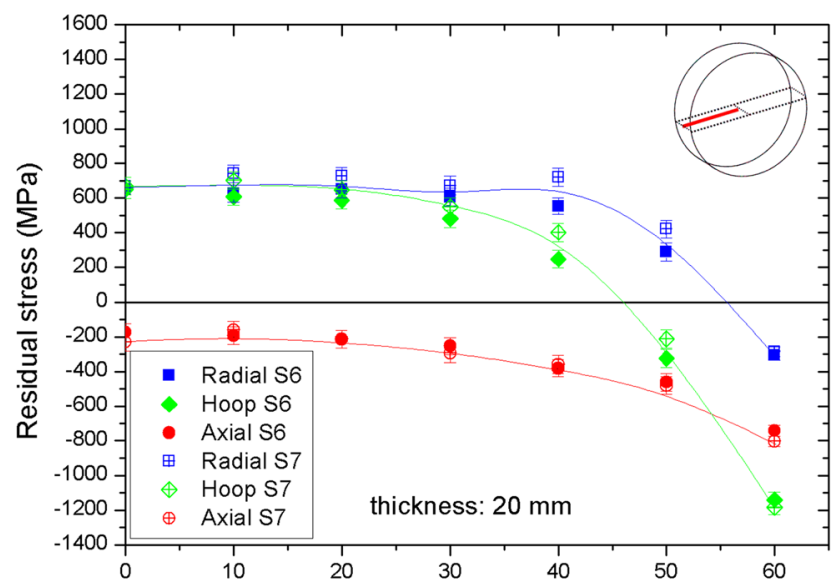

Distance from the geometric center in radial direction $(\mathrm{mm})$

(a)

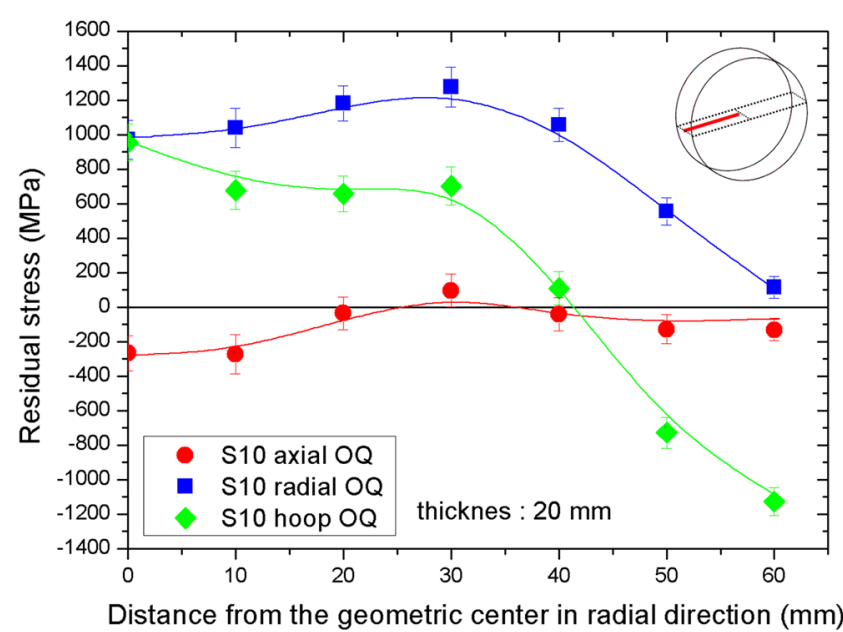

(b)

Fig. 3-Residual stresses in the as-quenched condition for (a) Inconel $718^{[19]}$ and (b) Udimet 720 LI disks. The graph on the left shows the ex situ axial profiles and the one on the right shows the ex situ radial profiles. The fit lines in (a) Inconel 718 represent the average stress profile from the different sample measurements.

the sample, $\varepsilon_{\text {radial }}=\varepsilon_{\text {hoop }}$ eliminating the need for a third measurement direction.

\section{RESULTS AND DISCUSSIONS}

\section{A. Quench-Induced Residual Stresses}

Figure 3 displays the radial and axial stress profiles for (a) Inconel 718 and (b) Udimet 720LI. It can be seen that the maximum residual stresses for the $20-\mathrm{mm}$-thick pucks after quenching appear in Udimet 720LI to be nearly double those in Inconel 718. Such dramatic differences are not surprising as Udimet 720LI has a significantly better high-temperature capability than Inconel 718 and also forms $\gamma^{\prime}$ precipitates even during oil quenching, while Inconel 718 tends to retain the $\gamma^{\prime}$ and $\gamma^{\prime \prime}$ stabilizing elements in solution during quenching. ${ }^{[1]}$ Hence, Udimet 720 LI already precipitation strengthens during quenching and can sustain high residual stresses. Figure 3(a) shows that in the axial 


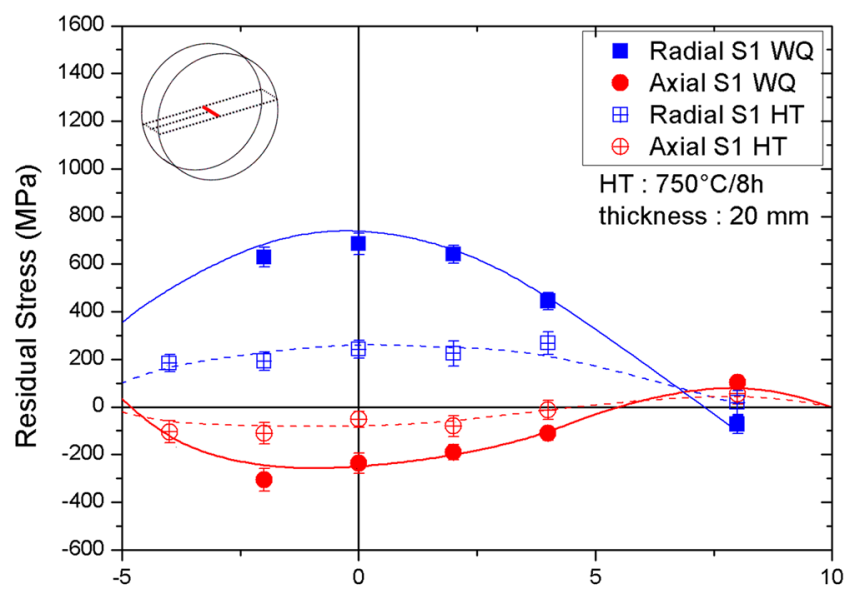

Distance from the geometric center in axial direction $(\mathrm{mm})$

(a)

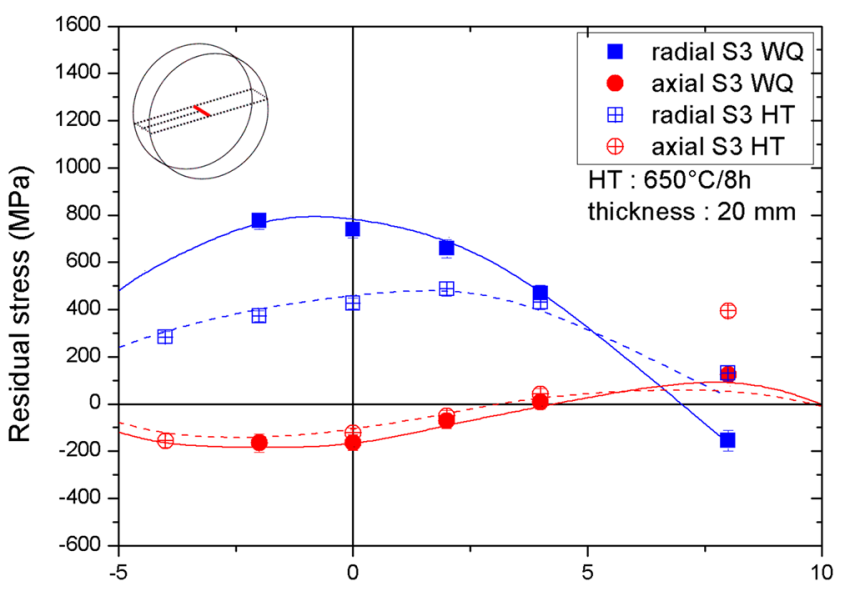

Distance from the geometric center in axial direction $(\mathrm{mm})$

(c)

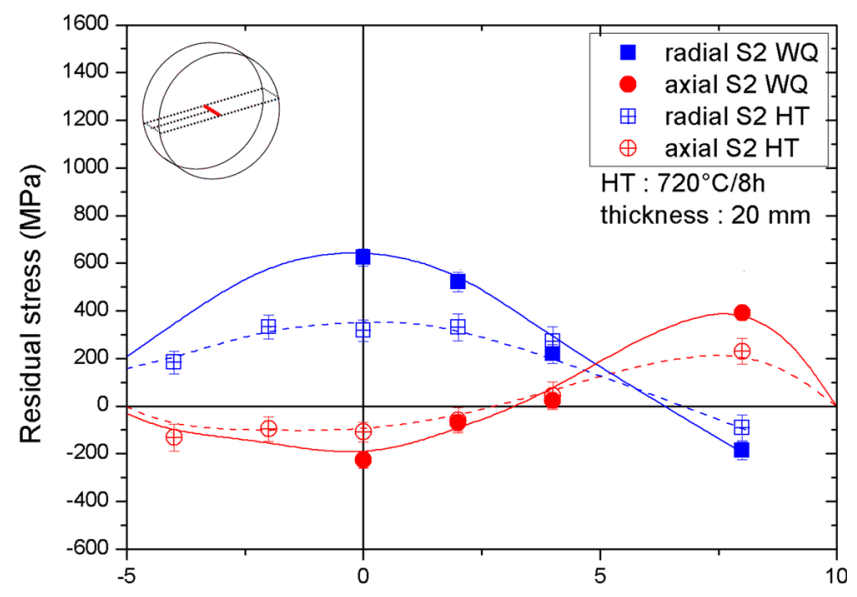

Distance from the geometric center in axial direction $(\mathrm{mm})$

(b)

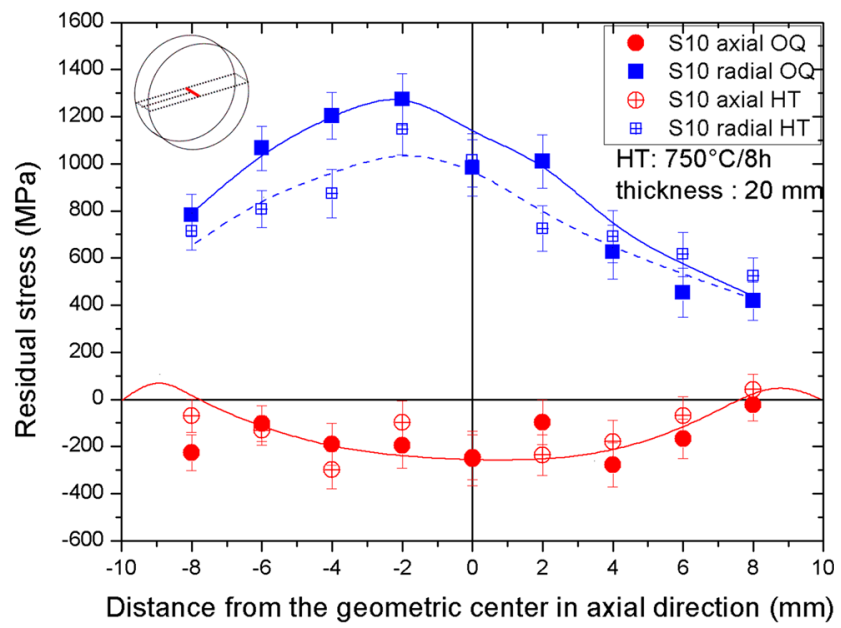

(d)

Fig. 4-Ex situ stress profiles in 20-thick samples of Inconel 718 before (continuous) and after (dashed) heat treatments at $(a) 750{ }^{\circ} \mathrm{C} / 8 \mathrm{~h},{ }^{[19]}(b)$ $720{ }^{\circ} \mathrm{C} / 8 \mathrm{~h}$, and $(c) 650{ }^{\circ} \mathrm{C} / 8 \mathrm{~h}$, measured on VULCAN compared with $(d)$ that for Udimet $720 \mathrm{LI}$ heat treated at $750^{\circ} \mathrm{C} / 8 \mathrm{~h}$ and measured on SALSA.

direction the quench stresses are characteristically parabolic for Inconel 718, as is commonly seen for the through-thickness residual stresses upon quenching plates. ${ }^{[4-6]}$ However, the maximum tensile stress values in Inconel 718 are found to be approximately $150 \mathrm{MPa}$ higher in the present work than in References 4 through 6 where the maximum tensile stress values did not exceed $500 \mathrm{MPa}$. The reason for this may arise from the different geometry of quenched components as well as divergences in the quenching procedures such as variations in the transfer duration from the furnace to the quench tank. For Udimet 720LI, Figure 3(b), the residual stress variation in the axial direction is somewhat asymmetric (possibly due to some asymmetric distortion of the quenched disks), but the most notable feature is that the tensile nature of the in-plane stresses extend to within $2 \mathrm{~mm}$ of the surface of the puck. This may result from experimental uncertainties combining positioning error in the distorted sample and measuring error which exceeds $\pm 100 \mathrm{MPa}$ in Udimet
720LI. In order to maintain stress balance, a steep stress gradient with strong compressive stress is to be expected toward the axial surface. Such a stress profile was formerly reported by Rist et al. ${ }^{[5]}$ and Dye et al. ${ }^{[6]}$ The stresses in Udimet 720LI are similar to the levels recorded by Rolph et al. for RR 1000. ${ }^{[15]}$ The residual stress profiles with radial distance from the center of the puck are broadly similar to that observed by Rolph et $a l .{ }^{[15]}$ being tensile in the center and becoming compressive toward the edge for the hoop stress as required by stress equilibrium, while the radial stress tends to zero close to the radial surface. The axial stress should be approximately zero throughout the pucks. The reason for the apparent lack of axial stress balance across the radial center line is not clear. It is most likely related to experimental uncertainties. It should be remembered when considering the overall balance of residual stress over the radial-axial cross section that the compressive core is balanced by tensile stresses around the periphery. 


\section{B. Effect of Aging Temperature}

Figure 4 displays the stress profiles for the radial and axial directions across the axial center line recorded on samples S1-S3 (Inconel 718) and S10 (Udimet 720LI) before and after aging. First of all, it is noticeable that there are some significant variations in residual stresses for the as-quenched conditions of the nominally identical samples S1-S3 although the overall profiles are very similar, Figures 4(a) through (c). The effect of aging temperature on the relaxation of the axial and radial stresses along the axial direction can be seen very clearly. Unsurprisingly the large radial stresses are relieved less effectively when a lower annealing temperature was applied translating into a 70, 50, and 40 pet reduction of maximum tensile stresses after 8 hours at $750{ }^{\circ} \mathrm{C}, 720^{\circ} \mathrm{C}$, and $650{ }^{\circ} \mathrm{C}$, respectively. By comparison the stresses for Udimet 720LI have reduced by only 20 pct even at $750{ }^{\circ} \mathrm{C}$, Figure 4(d), which is probably related to the higher creep resistance of Udimet 720LI compared to Inconel 718.

\section{Effect of Puck Thickness on Residual Stress}

Figure 5 displays the radial stress profiles prior to and post aging treatment for Inconel 718 hockey pucks with a thickness of 15,20 , and $25 \mathrm{~mm}$. It is clear from these results that the puck thickness appears to have very little effect on the residual stresses either before or post aging treatment certainly to within the scatter within the measurements. This similarity in residual stresses seems to be mainly driven by the fact that no significant axial stresses develop up to a thickness of $25 \mathrm{~mm}$. Since the diameter of the samples remained unchanged, it is not surprising that the mid-thickness radial stresses were independent of the thickness of the hockey pucks. As it can be seen in Figure 4(c), the hoop stresses are found to become compressive toward the surface as required by stress equilibrium. The amplitude of compressive hoop stresses seems to be higher for the thicker samples. However, such difference of magnitude may also be related to higher measurement uncertainties and positioning error which may have a significant impact when measuring close to the surface where the stress gradient is greatest.

\section{Time-Dependent Evolution of Residual Stress During Aging}

Stress relaxation profiles were recorded in the axial and radial directions in the center of the samples during the in situ heat treatments. As the axial stresses in Inconel 718 were small and the associated changes with annealing time within the uncertainty, only the radial stress evolutions are presented in Figure 6 for Inconel 718. It should be noted that the annealing experiment at $720{ }^{\circ} \mathrm{C}$ were carried out on hockey pucks of 15 and 25 $\mathrm{mm}$ thickness, while the annealing experiment at $650{ }^{\circ} \mathrm{C}$ and $750{ }^{\circ} \mathrm{C}$ were carried out on 20 -mm-thick hockey pucks. However, as demonstrated in Figure 5, the sample thickness variation of 15 to $25 \mathrm{~mm}$ does not have a significant effect on the residual stresses in the as-quenched and post-annealed conditions. The average uncertainty of the stress data for Inconel 718 was about $\pm 50 \mathrm{MPa}$. The first important observation for Figure 6 is that the starting stresses vary quite dramatically, which indicates very significant sample-to-sample variation; this emphasizes the importance of in situ characterization. In all cases, a significant drop in the radial stress is observed immediately upon reaching the annealing temperature being $400 \mathrm{MPa} / 65$ pct relief for $750{ }^{\circ} \mathrm{C}$, and approximately $300 \mathrm{MPa} / 45$ pct relief for $720{ }^{\circ} \mathrm{C}$ and $650{ }^{\circ} \mathrm{C}$. This suggests that most of the stresses are relieved by a combination of plastic deformation induced by the reduction of the yield strength with increasing temperature and power-law creep. The value of yield strength can vary from 300 to $1200 \mathrm{MPa}$ depending on the grain size of Inconel $718 .{ }^{[6]}$ However, the yield strength of annealed and quenched Inconel 718 is significantly lower than in aged condition. ${ }^{[26]}$ The stress drop occurring at the beginning of the heat treatment is therefore most likely related to plasticity resulting from the thermally induced yield strength reduction.

During the isothermal stage at $720{ }^{\circ} \mathrm{C}$ and $750{ }^{\circ} \mathrm{C}$ of the in situ experiments, only small levels of stress relaxation occurred over the hold time, while at $650^{\circ} \mathrm{C}$ essentially no time-dependent stress relaxation was detected. Table IV summarizes the stress relaxation functions calculated from the fit of the in situ data during the isothermal treatment. The tabulated parameters are relaxation coefficients which depend on material, temperature of the treatment, and initial stress level. These data suggest that a time-dependent deformation mechanism is involved in the stress relaxation at $720{ }^{\circ} \mathrm{C}$ and $750{ }^{\circ} \mathrm{C}$ since the creep relaxation rate is found to decrease with time and temperature in this temperature range. When considering Ashby creeps maps, ${ }^{[27]}$ one might conclude that initially power-law creep is the dominating mechanisms taken over by diffusional creep when the stress levels have reached low values. When comparing the two hockey puck samples heat treated at $720{ }^{\circ} \mathrm{C}$, it can be observed that the rate of stress relaxation clearly depends on the initial stress when the material has reached the intended temperature, with the 15 -mm-thick sample showing higher relaxation rates $(-11 \times \ln (\mathrm{t}))$ than the 25 -mm-thick sample $(-3 \times$ $\ln (t))$. Finally, the radial stress data measured at room temperature post the aging heat treatment show excellent agreement with the stress data recorded at the end of the in situ experiment. This is very encouraging providing great confidence in the in situ stress analysis.

Bapokutty et al. previously performed stress relaxation tests at various temperatures on tensile test samples in Inconel 718. ${ }^{[20]}$ When comparing their stress relaxation curves and stress values for stress relaxation at $750{ }^{\circ} \mathrm{C}$ and $650{ }^{\circ} \mathrm{C}$, excellent agreement can be found with Figure 6. Stress relaxation experiments on superalloy IN738LC also show similar trends as presented in Figure 6, although the difference in alloy composition and stress relaxation temperature makes this comparison less valid. ${ }^{[21]}$

The in situ data in Figure 6 demonstrate that a treatment at $750{ }^{\circ} \mathrm{C}$ promotes approximately $15 \mathrm{pct}$ 


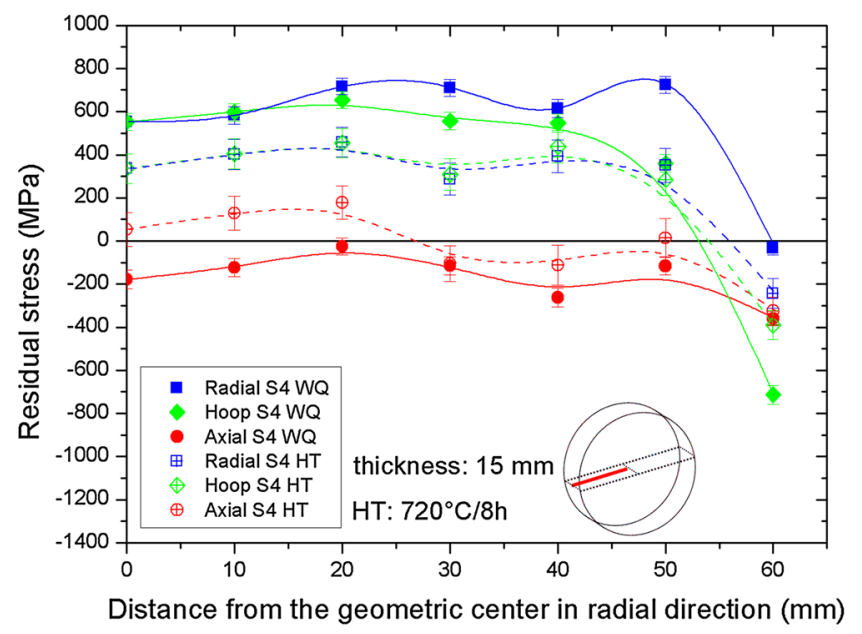

(a)

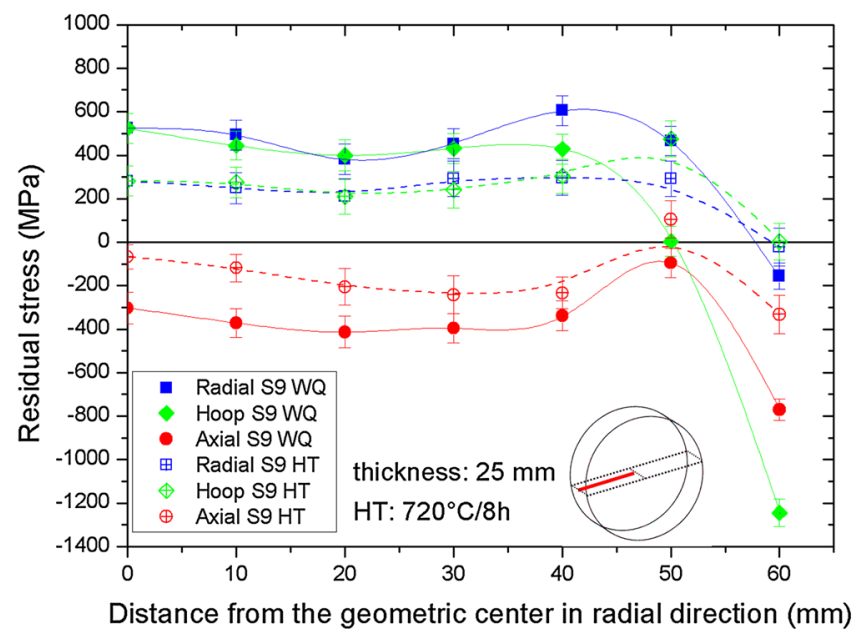

(c)

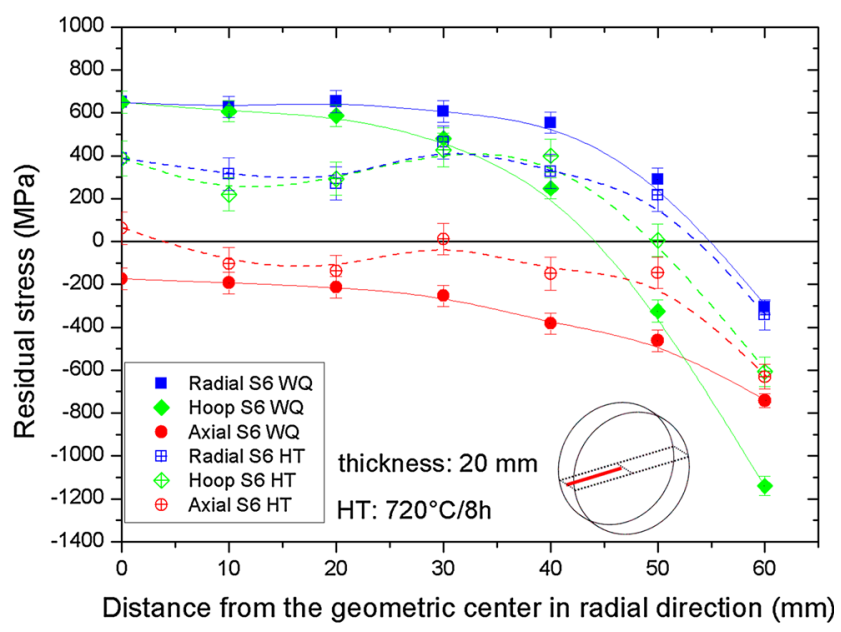

(b)

Fig. 5-Ex situ radial stress profiles before (continuous) and after (dashed) annealing at $720{ }^{\circ} \mathrm{C}$ for $8 \mathrm{~h}$ measured on Inconel 718 with (a) $15 \mathrm{~mm}$ thickness (S4), (b) $20 \mathrm{~mm}$ thickness (S6), and (c) $25 \mathrm{~mm}$ thickness (S9), all measured on KOWARI.

more stress relaxation than a treatment at $720^{\circ} \mathrm{C}$, with almost all the stress relaxation occurring during the heating stage. The industrial aging treatment of Inconel 718 usually includes a first step at $720{ }^{\circ} \mathrm{C}$ for 8 hours in order to form a combination of fine $\gamma^{\prime \prime}$ and $\gamma^{\prime}$ precipitates. ${ }^{[2]}$ However, the TTT diagram of Inconel $718^{[28]}$ indicates that heating to $750{ }^{\circ} \mathrm{C}$ directly followed by a cooling to $720{ }^{\circ} \mathrm{C}$ at the beginning of the treatment would not affect the phase distribution in Inconel 718, while it could help in reducing the residual stress amplitude by almost 15 pct.

Figure 7 shows the in situ stress relaxation data of Udimet 720LI (S10) collected on SALSA. As the maximum tensile stress level in Udimet 720LI was found $2 \mathrm{~mm}$ off the sample center, the in situ data were recorded in this point since it was more likely to exhibit a stronger in situ stress evolution than the center of the sample. The ex situ stress values presented in Figure 7 at the time $t=0$ and $t=12$ hours correspond to the measurements $2 \mathrm{~mm}$ off the center of the sample. As for Inconel 718, most of the stress relaxation occurs during the heating stage because of the reduction of the material yield strength with elevation of temperature. The observed stress drop is comparable to the yield strength reduction in Udimet $720 \mathrm{LI}$ at $750{ }^{\circ} \mathrm{C}$ reported by Daymond et al. in Reference 3 which indicates that stress relaxation is led by high-temperature plasticity. However, considering the very large radial stress, the stress relief during heating is comparatively small, which is most likely related to the high-temperature strength of Udimet 720LI compared to Inconel 718. ${ }^{[2,30]}$ The stress relaxation rate here was $-19 \times \ln (\mathrm{t})$ in the radial direction and $-4 \times \ln (\mathrm{t})$ in the axial direction. The average uncertainty of the stress data for Udimet 720LI exceeded $\pm 100 \mathrm{MPa}$. There is a mismatch between the last in situ data points and the ex situ measurements, which might result from measurement uncertainty which is significantly higher than for Inconel 718 . The poor neutron scattering properties for Udimet 720LI are mainly related to the relatively high Cobalt content, which is not present for Inconel 718 .

A comparison with the before mentioned in situ aging experiment on Ni-base superalloy RR $1000^{[15]}$ shows that the present data display far clearer trends due to a 
significant reduction in data scatter. There are most likely two reasons for the superior quality of the data in the present case. Inconel 718 and Udimet 720LI show less neutron absorption than RR1000 due to their chemical compositions (RR1000 containing more Cobalt and Hafnium than Inconel 718 and Udimet $720 \mathrm{LI}$ ), which are more favorable for neutron diffraction measurements. Secondly, the present in situ experiments were carried out with an optimized setup compared to Reference 15 and the strain scanning instruments VULCAN and SALSA have slightly higher flux than the ENGIN-X instrument at ISIS when only considering the 311 reflection. Hence, the work also demonstrates the need for higher flux neutron instruments as the planned BEER instrument at the European Spallation Source ${ }^{[31]}$ if one wants to move toward more in situ analysis.

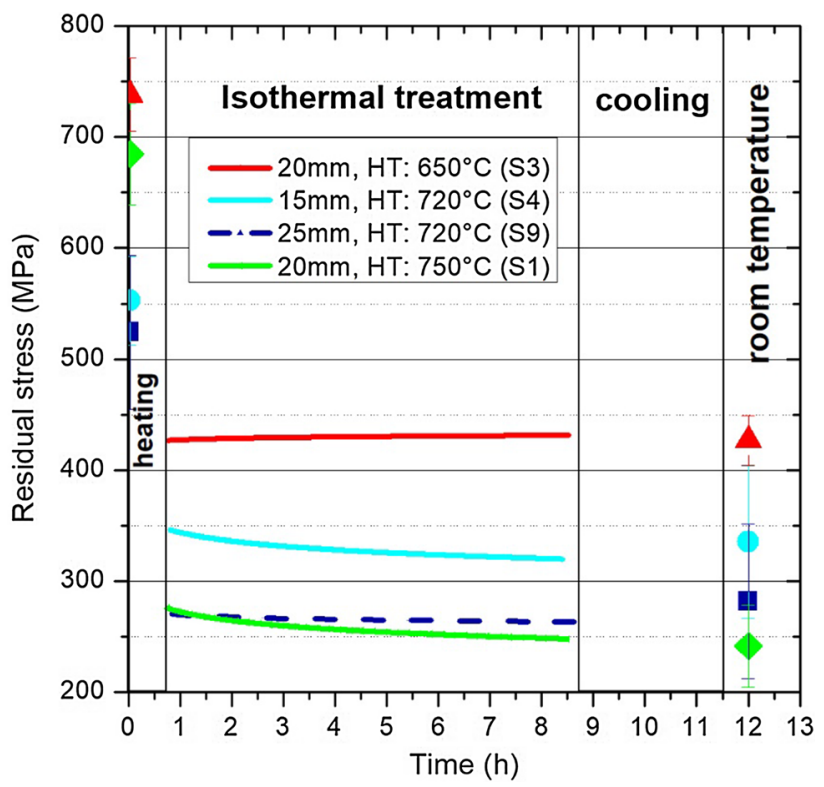

Fig. 6-Evolution of radial stresses in Inconel 718 when annealed at $650{ }^{\circ} \mathrm{C}, 720^{\circ} \mathrm{C}$, and $750{ }^{\circ} \mathrm{C} \cdot{ }^{[19]}$ Here, the points at $\mathrm{t}=0 \mathrm{~h}$ and at $\mathrm{t}=12 \mathrm{~h}$ correspond to ex situ measurements carried out at room temperature before and after the heat treatment. The experiments were carried out on VULCAN and KOWARI.

\section{CONCLUSIONS}

Stress relaxation induced by various aging thermal treatments in large superalloy forgings was investigated by a combination of ex situ and in situ neutron diffraction measurements. A new induction heating setup specifically designed for such experiments enabled in situ heat treatments to be performed with good repeatability. The quenching-induced residual stresses and aging-induced stresses were mapped ex situ in samples of different thicknesses in Inconel 718 and in an Udimet 720LI sample. The measurements were carried out on three different strain scanning instruments, demonstrating the versatility of the heating setup and feasibility of such experiments on different neutron diffractometers. The following conclusions can be drawn:

1. Udimet $720 \mathrm{LI}$ develops 40 pct higher level of stresses than Inconel 718 during quenching most likely due to $\gamma^{\prime}$ precipitation strengthening during quenching in Udimet $720 \mathrm{LI}$, which is not expected to happen in Inconel 718.

2. Udimet $720 \mathrm{LI}$ is significantly more resistant to stress relief by heat treatment than Inconel 718.

3. The sample thickness was found to have only a very little effect on the stress distribution following quenching- and aging-induced stress relaxation. Further experimentation would be required to study the effect of smaller diameter-to-thickness ratio on the stress distribution.

4. The amplitude of quenching-induced stresses measured in Inconel 718 was found to be approximately $200 \mathrm{MPa}$ higher in the present study than in previous works, which is most likely related to differences in the sample geometry and quenching procedures. The quenching process was found to be poorly reproducible in terms of stress distribution.

5. The in situ measurements revealed that for accurate analysis of strain and stress evolution it is vital to monitor the microstructurally driven $d_{0}$ evolution.

6 . The creep relaxation rates increase with the temperature and the initial value of residual stress in the as-quenched samples. For all annealing temperatures, it was found that almost 90 pet of the residual stresses are relieved during heating, while the isothermal hold either gave no or only slight further reduction in residual stresses. This means that the hold temperature is much more important than the hold time in terms of the efficacy of stress annealing.

Table IV. Stress Relaxation Functions Calculated from the Fit of the In Situ Data

\begin{tabular}{|c|c|c|c|c|c|c|}
\hline \multirow[b]{3}{*}{ Thickness } & \multicolumn{5}{|c|}{ Inconel 718} & \multirow{3}{*}{$\begin{array}{c}\text { Udimet } 720 \mathrm{LI} \\
750{ }^{\circ} \mathrm{C} \\
20 \mathrm{~mm}\end{array}$} \\
\hline & \multirow{2}{*}{$\begin{array}{l}650{ }^{\circ} \mathrm{C} \\
20 \mathrm{~mm}\end{array}$} & \multicolumn{3}{|c|}{$720^{\circ} \mathrm{C}$} & \multirow{2}{*}{$\begin{array}{l}750{ }^{\circ} \mathrm{C} \\
20 \mathrm{~mm}\end{array}$} & \\
\hline & & $15 \mathrm{~mm}$ & $20 \mathrm{~mm}$ & $25 \mathrm{~mm}$ & & \\
\hline Axial & - & $3 \times \ln (\mathrm{t})$ & $0.7 \times \ln (\mathrm{t})$ & $14 \times \ln (\mathrm{t})$ & $31 \times \ln (\mathrm{t})$ & $-4 \times \ln (\mathrm{t})$ \\
\hline Radial/Hoop & - & $-11 \times \ln (\mathrm{t})$ & $-9.7 \times \ln (\mathrm{t})$ & $-3 \times \ln (\mathrm{t})$ & $-11 \times \ln (\mathrm{t})$ & $-19 \times \ln (\mathrm{t})$ \\
\hline
\end{tabular}




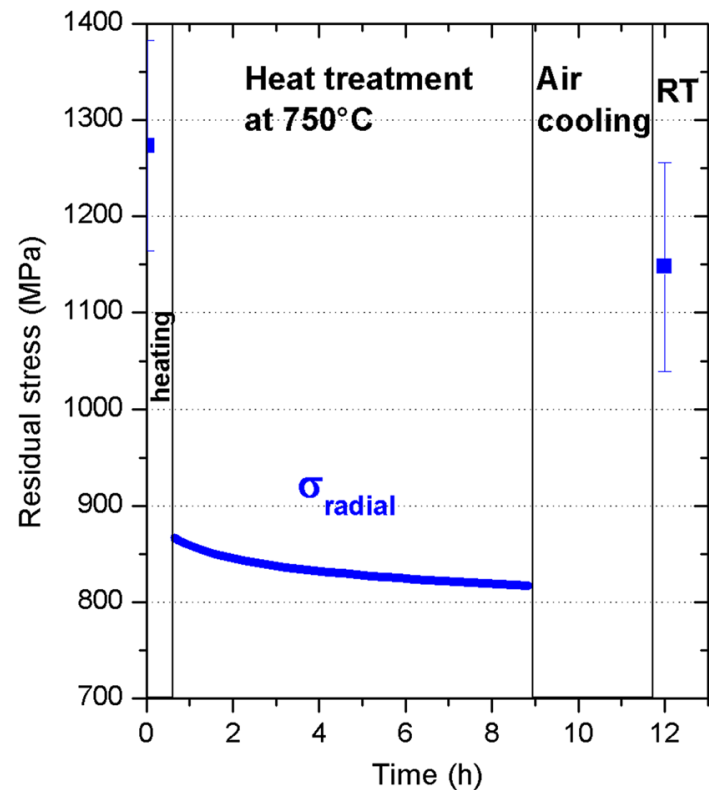

Fig. 7-Evolution of radial stress in Udimet 720LI when heat treated at $750{ }^{\circ} \mathrm{C}$. In this case, the hockey puck has a thickness of $20 \mathrm{~mm}$ and the experiment was carried out on SALSA.

7. An annealing treatment of Inconel $718{ }^{\circ} \mathrm{C}$ at $750{ }^{\circ} \mathrm{C}$ promotes approximately 15 pct more stress relaxation than a treatment at $720^{\circ} \mathrm{C}$.

8. In situ measurements suggest that a brief annealing step at $750{ }^{\circ} \mathrm{C}$ followed by cooling to $720{ }^{\circ} \mathrm{C}$ or even lower temperatures could significantly increase stress relaxation compared to single-step annealing at $720{ }^{\circ} \mathrm{C}$ without potentially compromising the microstructure of Inconel 718 according to Reference 28.

For all in situ experiments, it was possible to fit the stress relaxation data by using logarithmic functions. These functions in combination with the ex situ stress profiles determined in the present study can be used as input data or to validate process models for stress relief.

\section{ACKNOWLEDGMENTS}

This work was carried as part of a $\mathrm{Ph} . \mathrm{D}$. project sponsored by the Institut Max Von Laue - Paul Langevin (ILL), France. The experimental program benefited from the use of the ILL Facility, the OPAL Facility of the Australian Nuclear Science and Technology Organization (ANSTO), Australia, and material supply from Aubert\&Duval. The neutron scattering work conducted at Oak Ridge National Laboratory's Spallation Neutron Source was sponsored by the Scientific User Facilities Division, Office of Basic Energy Sciences, U.S. Department of Energy.

\section{REFERENCES}

1. R.C. Reed: The Superalloys: Fundamentals and Applications, Cambridge University Press, Cambridge, 2006.

2. A. Chamanfar, L. Sarrat, M. Jahazi, M. Asadi, A. Weck, and A.K. Koul: Mater. Des., 2013, vol. 52, pp. 791-800.

3. M.R. Daymond, M. Preuss, and B. Clausen: Acta Mater., 2007, vol. 55 , pp. 3089-3102.

4. D. Dye, K.T. Conlon, and R.C. Reed: Metall. Mater. Trans. A, 2004, vol. 35A, pp. 1703-13.

5. M.A. Rist, S. Tin, B.A. Roder, J.A. James, and M.R. Daymond: Metall. Mater. Trans. A, 2006, vol. 37A, pp. 459-67.

6. D. Dye, B.A. Roder, S. Tin, M.A. Rist, J.A. James, and M. R. Daymond, Superalloys 2004 10th Int. Symp., 2004, pp. 315-22.

7. U. Cihak, P. Staron, M. Stockinger, and H. Clemens: Adv. Eng. Mater., 2006, vol. 8 (11), pp. 1088-92.

8. P.J. Withers and H.K.D.H. Bhadeshia: Mater. Sci. Technol., 2001, vol. 17 , pp. $355-65$

9. M.P. Jackson and R.C. Reed: Mater. Sci. Eng. A, 1999, vol. 259 (1), pp. 85-97.

10. G.A. Rao, M. Kumar, M. Srinivas, and D.S. Sarma: Mater. Sci. Eng. A, 2003, vol. 355 (1-2), pp. 114-25.

11. M. Preuss, P.J. Withers, and G.J. Baxter: Mater. Sci. Eng. A, 2006, vol. 437 (1), pp. 38-45.

12. M. Karadge, B. Grant, P.J. Withers, G. Baxter, and M. Preuss: Metall. Mater. Trans. A, 2011, vol. 42A (8), pp. 2301-11.

13. T.P. Gabb, J. Telesman, P.T. Kantzos, P.J. Bonacuse, R.L. Barrie, and D.J. Hornbach: TMS Lett., 2004, vol. 1 (5), pp. 1-2.

14. M.T. Hutchings, P.J. Withers, T.M. Holden, and T. Lorentzen: Introduction to the Characterization of Residual Stress by Neutron Diffraction, CRC Press, Boca Raton, 2005.

15. J. Rolph, A. Evans, A. Paradowska, M. Hofmann, M. Hardy, and M. Preuss: C. R. Phys., 2012, vol. 13 (3), pp. 307-15.

16. X.-L. Wang, T.M. Holden, G.Q. Rennich, A.D. Stoica, P.K. Liaw, H. Choo, and C.R. Hubbard: Phys. B Condens. Matter, 2006, vol. 385, pp. 673-75.

17. O. Kirstein, U. Garbe, and V. Luzin: Mater. Sci. Forum, 2010, vol. 652 , pp. $86-91$

18. T. Pirling, G. Bruno, and P.J. Withers: Mater. Sci. Eng. A, 2006, vol. 437 (1), pp. 139-44.

19. P.E. Aba-Perea, T. Pirling, and M. Preuss: Mater. Des., 2016, vol. 110 , pp. $925-31$.

20. O. Bapokutty, Z. Sajun, and J. Syarif: J. Appl. Sci., 2012, vol. 12 (9), pp. 870-75.

21. J. Beddoes and T. Mohammadi: J. Strain Anal. Eng. Des., 2010, vol. 45 (8), pp. 587-92.

22. H.J. Stone, T.M. Holden, and R.C. Reed: Scripta Mater., 1999, vol. 40 (3), pp. 353-58.

23. M. Preuss, P.J. Withers, J.W.L. Pang, and G.J. Baxter: Metall. Mater. Trans. A, 2002, vol. 33A (10), pp. 3227-34.

24. R.C. Wimpory, C. Ohms, M. Hofmann, R. Schneider, and A.G. Youtsos: Int. J. Press. Vessel. Pip., 2009, vol. 86 (1), pp. 48-62.

25. P.E. Aba-Perea, T. Pirling, P.J. Withers, J. Kelleher, S. Kabra, and M. Preuss: Mater. Des., 2016, vol. 89, pp. 856-63.

26. H.L. Eiselstein and D.J. Tillack, Superalloys, 718 625, TMS, 1991.

27. H.J. Frost and M.F. Ashby: Deformation Mechanism Maps: The Plasticity and Creep of Metals and Ceramics, Pergamon Press, Oxford, 1982.

28. A. Oradei-Basile and J.F. Radavich, Superalloys 718 625, TMS, 1991, pp. 325-35.

29. D.U. Furrer and H.-J. Fecht, Superalloys 2000 9th Int. Symp., 2000, pp. 415-24.

30. S. Metals, Inconel alloy 718, Publ. No. SMC-045, Spec. Met. Corp. Huntington, WV, USA, 2007.

31. J. Fenske, M. Rouijaa, J. Šaroun, R. Kampmann, P. Staron, G. Nowak, J. Pilch, P. Beran, P. Šittner, and P. Strunz: J. Phys. Conf. Ser., 2016, vol. 746 (1), p. 12009.

Publisher's Note Springer Nature remains neutral with regard to jurisdictional claims in published maps and institutional affiliations. 